\title{
A ORGANIZAÇÃO DOS SISTEMAS DE ENSINO NOS PAÍSES DO MERCOSUL
}

\author{
LA ORGANIZACION DE SISTEMAS DE EDUCACION EN LOS PAÍSES DEL \\ MERCOSUR
}

THE ORGANIZATION OF EDUCATION SYSTEMS IN MERCOSUR COUNTRIES

\author{
Kellcia Rezende SOUZA ${ }^{1}$ \\ Maria Teresa Miceli KERBAUY ${ }^{2}$
}

RESUMO: O artigo busca analisar a normatização da organização dos sistemas de ensino nos países do Mercosul (Argentina, Brasil, Paraguai, Uruguai e Venezuela) e sua relação com o direito à educação. A partir da metodologia do estudo comparado foi realizada uma pesquisa bibliográfica e documental com enfoque qualitativo. A fonte documental se constituiu nas Constituições vigentes dos países que compõem o referido bloco e a Legislação educacional (Lei de Diretrizes e Bases e/ou legislação equivalente). Os resultados mensurados apontam que o Brasil dispõe de um arcabouço constitucional mais amplo sobre a organização educacional. Argentina, Paraguai, Uruguai e Venezuela demandam a legislação infraconstitucional para regulamentar a estruturação da Educação. Porém, mesmo com a proteção jurídica mais sólida na sua Carta Magna, o Brasil carece de um marco legal que normatize seu Sistema Nacional de Educação, diferentemente dos demais países do Mercosul, que instituíram essa estruturação em suas respectivas legislações educacionais.

PALAVRAS-CHAVE: Mercosul. Políticas educacionais. Sistemas de ensino.

RESUMEN: El artículo busca analizar la normatización de la organización de los sistemas de enseñanza en los países del Mercosur (Argentina, Brasil, Paraguay, Uruguay y Venezuela) y su relación con el derecho a la educación. A partir de la metodología del estudio comparado se realizó una investigación bibliográfica y documental con enfoque cualitativo. La fuente documental se constituyó en las Constituciones vigentes de los países que componen el referido bloque y la Legislación educativa (Ley de Directrices y Bases y / o legislación equivalente). Los resultados mensurados apuntan que Brasil dispone de un marco constitucional más amplio sobre la organización educativa. Argentina, Paraguay, Uruguay y Venezuela demandan de la legislación infraconstitucional para reglamentar la estructuración de la educación. Sin embargo, incluso con la protección jurídica más sólida en su Carta Magna, Brasil carece de un marco legal que normatice su Sistema Nacional de Educación, a diferencia de los demás países del Mercosur, que instituyeron esa estructuración en sus respectivas legislaciones educativas.

\footnotetext{
${ }^{1}$ Universidade Federal da Grande Dourados (UFGD). Dourados, MS - Brasil. Professora adjunta da Universidade Federal da Grande Dourados e do Programa de Pós-Graduação em Administração Pública. Doutora em Educação Escolar pela Universidade Estadual Paulista. ORCID: https://orcid.org/0000-0002-8663-4615. E-mail: kellcia@hotmail.com

${ }^{2}$ Universidade Estadual Paulista (UNESP). Araraquara, SP - Brasil: Professora da Universidade Estadual Paulista (Unesp)/Campus Araraquara e dos Programas de Pós-Graduação em Educação Escolar e Ciências Sociais. Doutora em Ciências Sociais pela Pontifícia Universidade Católica de São Paulo. ORCID: https://orcid.org/0000-00020622-1512. E-mail: teresa.kerbauy@gmail.com
} 
PALABRAS CLAVE: Mercosur. Políticas educativas. Sistemas de enseñanza.

ABSTRACT: The article seeks to analyze the regulation of the organization of education systems in the Mercosur countries (Argentina, Brazil, Paraguay, Uruguay and Venezuela) and their relationship with the right to education. Based on the methodology of the comparative study, a bibliographic and documentary research with a qualitative approach was carried out. The documentary source was constituted in the current Constitutions of the countries that make up the mentioned block and the educational Legislation (Law of Guidelines and Bases and / or equivalent legislation). The results indicate that Brazil has a broader constitutional framework regarding the educational organization. Argentina, Paraguay, Uruguay and Venezuela demand infra-constitutional legislation to regulate the structuring of education. However, even with the strongest legal protection in its Magna Carta, Brazil lacks a legal framework that regulates its National Education System, unlike the other Mercosur countries, which instituted this structuring in their respective educational legislations.

KEYWORDS: Mercosur. Educational policies. Teaching systems.

\section{Introdução}

O contexto mundial, ao longo dos últimos anos, vem se caracterizando por transformações econômicas, sociais e políticas. Essa dinâmica, decorrente do processo de globalização, tem imposto uma reconfiguração nas relações estabelecidas entre os países, estimulando, desse modo, a criação de blocos regionais com o intuito de assegurar o fortalecimento da inserção geopolítica e econômica da nova ordem mundial. Diante desse cenário, a educação tem-se constituído enquanto instrumento de integração que visa assegurar o desenvolvimento econômico com justiça social.

O Mercado Comum do Sul (Mercosul) foi criado nesse contexto, pelo Tratado de Assunção em 1991, com o objetivo de promover a livre circulação de bens, serviços e capitais entre os países do Cone Sul - Argentina, Brasil, Paraguai e Uruguai ${ }^{3}$, por meio da eliminação dos direitos alfandegários e restrições não tarifárias de mercadorias. Trata-se de um pacto regional para o fortalecimento econômico dos respectivos países. Em 2012, a Venezuela ingressou como quinto país membro do bloco (SOUZA, 2017).

Embora o Mercosul seja um acordo que abarca eminentemente o setor econômico e comercial, incorpora, desde o início, outros setores que possuem estrita relação com o

${ }^{3} \mathrm{O}$ recorte do estudo delimita apenas os países pertencentes ao Mercosul. Dessa forma, não atentaremos à discussão dos Estados Associados - Chile, Bolívia, Colômbia, Equador e Peru, assim como os demais países latino-americanos, cuja realidade econômica, social e, dentro desta, educacional, apresenta muitos traços de similaridade (BABINSKI, 2010). 
desenvolvimento político, econômico e social dos Estados que o integram, dentre eles, a Educação. Denota-se, portanto, que o ingresso da Educação na agenda do Mercosul demonstra uma diversificação na pauta do bloco, que foi criado com a finalidade de fortalecer a economia regional.

Nesse viés, o presente trabalho tem como objetivo analisar a normatização da organização dos sistemas de ensino nos países do Mercosul (Argentina, Brasil, Paraguai, Uruguai e Venezuela). A fim de propiciar o alcance do objetivo proposto foi realizada, a partir da metodologia de estudo comparado, uma pesquisa bibliográfica e documental com enfoque qualitativo. A fonte documental se constituiu nas Constituições vigentes dos países que compõem o referido bloco e a Legislação educacional (Lei de Diretrizes e Bases e/ou legislação equivalente).

\section{Sistemas de ensino dos países do Mercosul}

Sistema de Ensino, segundo Saviani (2010), compreende um conjunto de instituições de ensino (Públicas e Privadas) de diferentes níveis e modalidades de educação, bem como de órgãos educacionais, administrativos e normativos distintos, mas, ao mesmo tempo, interdependentes, que interagem entre si com unidade. É articulado por fins em comum e respaldado por normas elaboradas pelo órgão competente, que visam ao desenvolvimento do processo educativo em um país. Nesse sentido, vejamos a seguir como são regulamentados os sistemas de ensinos dos países membros do Mercosul.

A Constituição Argentina destaca, em seu artigo $5^{\circ}$, que as províncias devem regulamentar suas respectivas constituintes no âmbito do sistema republicano e assegurar a administração da justiça, do regime municipal e da educação primária. Para isso, o governo federal deverá garantir as condições plenas para o exercício das instituições em cada província (ARGENTINA, 1994).

A constituinte da Argentina estabeleceu às províncias, desse modo, os poderes não delegados ao governo nacional. Essas unidades federativas detêm a competência remanescente ou residual para legislar, podendo definir suas respectivas constituições, criando suas próprias instituições e definir legislações específicas voltadas paras as áreas sociais, dentre elas, a educação. Por outro lado, na Argentina, embora os entes federados sejam de natureza nacional, provincial e municipal, em que as províncias são equivalentes aos estados brasileiros, os 
municípios não dispõem das mesmas competências educacionais específicas, pois não são instituídos como entes federados autônomos.

Nos artigos $5^{\circ}$ e $6^{\circ}$ da Lei de Educação Nacional nº 26.206/2006, destacam-se a organização e as responsabilidades dos federados no país para com a educação. Nesse viés, o Estado Nacional é quem define as diretrizes das políticas educacionais no âmbito da estruturação de uma unidade. Isso não implica em deixar de reconhecer as particularidades regionais das províncias, que deverão definir suas distintas normativas educacionais de acordo com suas respectivas realidades e necessidades, porém, devem estar em consonância com os pressupostos comuns estabelecidos pelo Estado Nacional para todo o país (ARGENTINA, 2006).

A perspectiva da unidade da organização educacional da Argentina é respaldada pela institucionalização de um Sistema Nacional de Educação. A normatização desse Sistema é assegurada em um capítulo da Lei de Educação Nacional nº. 26.206/2006. Essa legislação prevê que competem ao Estado Nacional, às Províncias e à Cidade Autônoma da Buenos Aires a responsabilidade pelo planejamento, organização, supervisão e financiamento do Sistema Educativo do país, bem como do reconhecimento, autorização e fiscalização das instituições de ensino públicas, filantrópicas e privadas.

Frente a essa perspectiva, a Lei Argentina define que o Sistema Nacional de Educação é o conjunto organizado de serviços e atividades educacionais regulados pelo Estado e que permitem o exercício do direito à educação. Eles integram serviços educacionais de gerenciamento de Estado e a gestão cooperativa privada e social de todas as jurisdições do país, cobrindo os diferentes níveis, ciclos e modalidades da educação.

Denota-se a compreensão, no tocante à referida lei, da relação entre a organização de um sistema nacional com a efetivação do direito à educação. A consolidação de um Sistema Nacional de Educação representa a ação sistematizada das instituições educacionais de um país, o que significa uma ação intencional conforme objetivos previamente formulados (SAVIANI, 2010). Essa compreensão demonstra o compromisso da Argentina, no âmbito jurídico, com a estruturação unificada da educação no país como uma condição para a materialização do direito educacional.

Desse modo, a estrutura do Sistema Educacional do país compreende quatro níveis: a educação inicial, a educação primária, a educação secundária e a educacional superior, além das oito modalidades educacionais: Educação técnico-profissional; Educação especial; Educação de Jovens e Adultos; Educação Artística; Educação intercultural bilíngue; Educação Rural; Educação em Contextos de Privação de Liberdade; Educação Domiciliar e Hospitalar. 
Sobre a estrutura da educação básica argentina, a Lei de Educação Nacional $\mathrm{n}^{\circ}$. 26.206/2006 define a educação inicial como uma unidade pedagógica e compreende as crianças de 45 dias até os cinco anos de idade, sendo este último obrigatório. A educação inicial é dividida em dois ciclos: os jardins maternais, para as crianças de 45 dias até os dois anos de idade, e os jardins infantis, para as de três a cinco anos. A educação primária é obrigatória e constitui uma unidade pedagógica organizativa destinada à formação das crianças a partir dos seis anos de idade. $\mathrm{O}$ ensino secundário é obrigatório e trata-se de uma unidade pedagógica e organizacional destinada aos adolescentes e jovens que têm conhecimento de nível de educação primária. Na Argentina, as etapas da educação básica são denominadas de unidade pedagógica (ARGENTINA, 2006).

A legislação da Argentina reforçou a presença do Estado Nacional no tocante à definição de um marco legal e das diretrizes para as políticas educacionais, assim como estabeleceu uma estruturação unificada do sistema educativo do país, sendo a educação inicial, primária e secundária de responsabilidade das províncias e Cidade Autônoma de Buenos Aires. Por outro lado, ressaltou a obrigação, em conjunto, de todos os entes federados na universalização do atendimento escolar das crianças de quatro anos. Ademais, instituiu que o Estado Nacional tem a incumbência de criar e financiar as universidades públicas (ARGENTINA, 2006).

Observamos que a legislação argentina organizou a estruturação educacional a partir da institucionalização de um sistema unificado de ensino e definiu os princípios, objetivos e fins de sua respectiva política educacional nacional, bem como as competências dos entes federados referentes aos seus níveis educacionais. No Brasil, a Constituição Federal de 1988 sofreu alterações a partir de Emendas no tocante ao tema.

É importante enfatizar, inicialmente, que assim como a Argentina, a organização político-administrativa do Estado Brasileiro é constituída pela federação. Para Araujo (2010), o Estado Federado apresenta a distribuição interdependente político-administrativa. O Estado é dividido verticalmente, de modo que os distintos níveis de governo têm autoridade sobre a mesma população e território.

Além da relação de interdependência, o federalismo tem como pressuposto uma organização territorial e política que visa garantir, pela via democrática, a repartição de responsabilidades governamentais, ao mesmo tempo em que esteja assegurada a integridade do Estado nacional frente às inúmeras disputas e desigualdades regionais. Portanto, a federação é uma forma de Estado regida pelo princípio da igualdade política de coletividades regionais e desiguais (ARAUJO, 2010). 
Tratar da organização federativa da educação brasileira, portanto, implica aprofundar a discussão sobre a legislação em vigência para o relacionamento entre os entes federados. No artigo 211 da Carta Magna brasileira, é assegurado que a União, os Estados, o Distrito Federal e os Municípios organizarão, em regime de colaboração, seus sistemas de ensino. Assim sendo, a organização da educação nacional, conforme o evidenciado, reflete a organização federativa do País e pressupõe o funcionamento de sistemas de ensino distintos: sistema federal, sistema estadual e do Distrito Federal, e sistema municipal.

Assim, a Constituição Federal delineia, objetivamente, as bases da República Federativa do Brasil, ao afirmar que: Art. $1^{\circ}$ A República Federativa do Brasil, formada pela união indissolúvel dos Estados e Municípios e do Distrito Federal, constitui-se em Estado Democrático de Direito (BRASIL, 1988). Essa união indissolúvel entre os entes federados se efetiva, segundo Dourado (2013), na complexa relação de coordenação e autonomia, para garantir a todos os direitos sociais, entre eles, a educação. $\mathrm{O}$ autor também destaca que o federalismo brasileiro apresenta uma tipologia inédita e diferente da Argentina, ao incluir os municípios com prerrogativas autônomas para a organização político-administrativa.

Os dispositivos constitucionais vão tecendo, desse modo, a dinâmica basilar do federalismo brasileiro e a necessidade de regulamentação da cooperação entre os entes federados, que, a despeito de gozarem de autonomia, contam com competências privativas, comuns e concorrentes, que não os descaracterizam, mas que devem se efetivar por meio de relações de cooperação, onde a dinâmica nacional de garantia de direitos se firma como diretriz. Esta, por sua vez, não secundariza a singularidade da ação dos entes federados, mas, ao contrário, fortalece tais ações, a partir de parâmetros nacionais de garantia dos direitos e do bem-estar nacional (DOURADO, 2013, p. 767).

A LDB/1996 retoma os princípios de organização de sistema de ensino definidos pela Constituição Federal e apresenta mais detalhadamente as especificidades de cada ente federado, definindo a organização da educação em: Educação Básica, que compreende a educação infantil, o ensino fundamental e o ensino médio; Educação Superior, e as modalidades educacionais: Educação de Jovens e Adultos, Educação Especial e Educação Profissional (BRASIL, 1996).

A educação escolar brasileira, conforme artigo $n^{\circ} .21$ da sua Lei de Diretrizes e Bases, é composta por dois níveis: a educação básica e o ensino superior. A educação básica, por sua vez, é dividida por etapas: a educação infantil, o ensino fundamental e o ensino médio. A educação infantil é ofertada em instituições de ensino para crianças de zero a cinco anos. O ensino fundamental possui duração de nove anos, com o ingresso da criança a partir dos seis 
anos de idade, e está dividido em anos iniciais e finais. Já o ensino médio tem duração mínima de três anos (BRASIL, 1996).

O desenho jurídico da organização educacional brasileira se caracteriza pela divisão de competências e responsabilidades entre a União, os estados e municípios. Segundo Vieira (2001), essa estruturação obedece à mesma configuração político-administrativa da República, que se fundamenta pelo federalismo e prevê a descentralização normativa e executiva conforme os termos do artigo $\mathrm{n}^{\circ} .18$ da Carta Magna do país.

Para Cruz (2012), a divisão de responsabilidades entre os entes federados no Brasil, como expressada na Constituição Federal e também na Lei de Diretrizes e Bases do país, remete ao reconhecimento da ausência da sistematização de um sistema nacional de educação articulado para garantir uma organicidade à oferta do serviço educacional. Assim, embora a legislação brasileira defina a organização político-administrativa da educação fundamentada no federalismo e na descentralização das competências pelos níveis de ensino para cada ente federado, o país não dispõe da regulamentação de um sistema nacional de educação ancorado no regime de colaboração e no compartilhamento de responsabilidades.

Instituir o sistema nacional de educação constitui em um marco regulatório para o país e pode contribuir para a coordenação federativa em educação, sob as bases de um federalismo cooperativo na educação do país. Essa demanda está prevista na legislação infraconstitucional que regulamentou o Plano Nacional de Educação, a Lei n ${ }^{\circ}$. 13.005/2014, que em seu artigo $13^{\circ}$, definiu que o poder público deverá instituir, em normativa específica, contados 2 (dois) anos da publicação desta Lei, o Sistema Nacional de Educação, responsável pela articulação entre os sistemas de ensino, em regime de colaboração, para efetivação das diretrizes, metas e estratégias do Plano Nacional de Educação (BRASIL, 2014).

Araujo (2010) adverte que a falta de regulamentação de um regime de colaboração na área educacional como um sistema torna a tarefa de formulação, e posterior implementação de um Plano Nacional de Educação, ainda mais complexa. Independente desta lacuna, coordenar um sistema unificado a partir da articulação de 5570 municípios, 26 estados, um Distrito Federal e a União, por si só, envolve muitas variáveis e enormes dificuldades operacionais, exigindo um nível de trabalho conjunto ainda inexistente no Brasil.

Resulta das legislações brasileiras a ênfase no processo de descentralização, todavia, essa forma de organização não indica, necessariamente, a efetivação de um sistema plenamente descentralizado. "A efetiva descentralização vem-se constituindo em um grande desafio, visando à consolidação da dinâmica federativa do Estado brasileiro e à democratização do poder 
e dos processos decisórios nas suas diferentes estruturas organizacionais" (OLIVEIRA; MORAES; DOURADO, 2009, p. 02).

Assim, o Estado Brasileiro precisa definir e garantir as diretrizes e bases para a(s) lei(s) complementar(es) em consonância ao cumprimento do artigo 13 da Lei nº. 13.005/2014. Nessa ótica, a institucionalização do Sistema Nacional de Educação, compreendida como política de Estado, deve direcionar a garantia do direito à educação, envolvendo as diferentes esferas de governo e os sistemas de ensino no atendimento à população, em todos os níveis, etapas e modalidades de educação, em regime de corresponsabilidade, em que haja organicidade entre a capacidade financeira e as respectivas responsabilidades de cada ente federado, sem prejuízo das competências comuns e supletivas, tendo por eixo um regime de colaboração articulado e unificado (SAVIANI, 2010).

Se o sistema pode ser definido como a unidade de vários elementos intencionalmente reunidos de modo a formar um conjunto coerente e operante, conclui-se que o Sistema Nacional de Educação é a unidade dos vários aspectos ou serviços educacionais mobilizados por determinado país, intencionalmente reunidos de modo a formar um conjunto coerente que opera eficazmente no processo de educação da população do referido país. (SAVIANI, 2010, p. 381)

A Constituição Federal do Paraguai atribui como responsáveis pela educação a sociedade, em particular a família, o município e o Estado. $\mathrm{O}$ artigo $\mathrm{n}^{\circ} .76$ da Carta Magna do país, além de ressaltar que a educação básica é obrigatória e que o Estado deve promovê-la, bem como a educação secundária, técnica, agrícola, industrial e de ensino superior, registra que a organização do sistema de ensino é responsabilidade essencial do Estado, com a participação de diferentes comunidades educativas. Esse sistema irá abranger os setores público e privado, tanto no nível formal quanto informal (PARAGUAI, 1992).

O texto constitucional ainda estabelece as competências do governo departamental e dos municípios. $\mathrm{O}$ artigo $\mathrm{n}^{\circ} .163$ prevê a coordenação das ações dos departamentos em consonância com as atividades do governo central no que tange à saúde e à educação. O artigo $n^{\circ}$. 168, por sua vez, regulamenta que os municípios do país dispõem da atribuição da livre gestão da educação (PARAGUAI, 1992).

Embora a Carta Magna do país delimite responsabilidades aos departamentos e municípios, a organização, financiamento e avaliação do sistema de ensino no Paraguai são incumbências do Estado. A centralização das competências educacionais para o Estado contrasta com a perspectiva constitucional que, em seu artigo primeiro, define que o país é um Estado Unitário Descentralizado. Podemos depreender, conforme Trojan (2010), que a 
legislação que versa sobre a educação do Paraguai demonstra uma perspectiva de descentralização administrativa, ou seja, de distribuição da execução das decisões políticas tomadas pelo governo central.

A Lei Geral da Educação nº $1.264 / 1998$ regulamenta o sistema educacional do país e seus respectivos objetivos. A referida lei também estabelece, em seus artigos $n^{\circ} .5$ e 6 , que o sistema educacional paraguaio definirá as diretrizes curriculares básicas voltadas à educação básica e as modalidades de ensino, e destaca que o Estado promoverá a descentralização dos serviços educacionais públicas.

Ainda que o artigo $n^{\circ} .6$ enfatize a previsão da adoção de uma política de favorecimento à descentralização dos serviços educacionais para as autoridades locais, o sistema nacional de educação do Paraguai é centralizado no que se refere à tomada de decisões, ao financiamento, à avaliação, à gestão e a sua respectiva operacionalização (TROJAN, 2010)

$\mathrm{O}$ artigo $\mathrm{n}^{\circ} .12$ reitera as premissas regulamentadas na Constituição paraguaia da responsabilidade do Estado com a organização do sistema nacional. Já o artigo $\mathrm{n}^{\circ} .27$ define a estruturação formal da educação do país em três níveis: o primeiro compreende a educação inicial e educação escolar básica, que é obrigatória; o segundo contempla a educação média, e o terceiro a educação superior (PARAGUAI, 1998).

A educação inicial do Paraguai compreende três ciclos - maternal, infantil e pré-escolar - e é voltado para as crianças de zero a cinco anos. Já a educação escolar básica do país contempla nove graus e é dividida em três ciclos de três anos de período. A formação da educação média ocorre em um único ciclo com três anos de duração e voltada para as opões de bacharelado científico e técnico profissionalizante (PARAGUAI, 1998).

Além dos três níveis, o sistema paraguaio também regulamenta a pós-graduação e as seguintes modalidades educacionais: a Educação básica geral e continuada; Educação para grupos étnicos; Educação camponesa e rural; Educação para pessoas com limitações e com capacidades excepcionais; Educação para a reabilitação social; Educação militar e policial; Educação para religiosos (PARAGUAI, 1998).

Segundo Molinier (2014, p. 17), os instrumentos legais do Paraguai (Constituição de 1992 e Lei Geral da Educação de 1998) foram marcos institucionais que regulamentaram a histórica reivindicação de um sistema nacional de educação unificado como a base para um projeto democrático voltado para assegurar o direito à educação: "El marco normativo nacional paraguayo para asegurar el cumplimiento del derecho a la educación, consagrado constitucionalmente y canalizado con diferentes instrumentos jurídico-institucionales como base de un proyecto democrático posible". 
A Carta Magna do Uruguai define, no artigo nº. 202, que o Ensino Superior Público, secundário, primário, normal, industrial e artístico, será regido por um ou mais Conselhos Autônomos Administrativos. As entidades públicas serão ouvidas pelo conselho na elaboração das leis relacionadas aos seus serviços. Cabe à lei infraconstitucional assegurar a coordenação do ensino.

O conselho autônomo administrativo uruguaio destinado à educação é a Administração Nacional de Educação Pública (ANEP), ente autônomo com personalidade jurídica e responsável pela elaboração das políticas educacionais dos diferentes níveis de ensino, conforme os princípios gerais dispostos na Lei Geral da Educação. Na consecução de seus objetivos constam as atividades realizadas pelo Conselho Diretivo Central e os Conselhos Específicos para cada nível de ensino do país (BABINSKI, 2010).

Souza (2017) esclarece que a Administração Nacional de Educação Pública (ANEP) é um órgão estatal e tem a responsabilidade de planejar, administrar e gerir o sistema educacional Uruguaio público nos níveis da educação inicial, primária, média, técnica e formação terciária superior. O órgão também tem a competência de regulamentar o funcionamento das instituições privadas dos mesmos níveis.

Quanto às definições das competências dos departamentos, a Constituição Uruguaia determina, em seu artigo $n^{\circ}$. 202, que os governos departamentais podem atuar em consonância com outros e com o poder executivo, bem como com as entidades autônomas do país. Os departamentos executam de forma descentralizada a organização e prestação de serviços públicos e atividades próprias ou comuns, tanto em seus respectivos territórios e em forma regional ou interdepartamental (URUGUAI, 1967).

Quanto aos municípios, até 2009, o país organizava sua estrutura estatal pelo governo central e os 19 departamentos. Esse quadro foi alterado a partir da aprovação da Lei $\mathrm{n}^{\circ}$. 18.567/2009 denominada "Lei de Descentralização Política e Participação Cidadã", que modificou a estrutura estatal, instituindo o município, que passou a ser o terceiro nível de governo e de administração do país. A lei infraconstitucional prevê, em seu artigo $\mathrm{n}^{\circ}$. 12, que cabe aos governos municipais: "Colaborar en la gestión de políticas públicas nacionales cuando así se haya acordado entre el Gobierno Departamental y el Poder Ejecutivo" (URUGUAI, 2009).

Barreto (2012, p. 287) esclarece que essa legislação representa um marco histórico no caminho da constituição de um Estado Descentralizado e com mais autonomia nos níveis governamentais. Todavia, por se tratar de uma implantação legal recente, há várias dúvidas referentes " [...] aos poderes, às competências, à efetiva autonomia dos municípios, bem como 
ao modo como eles poderão cumprir suas obrigações e relacionar-se política e institucionalmente com as demais instâncias, especialmente o Intendente, ao qual estão diretamente vinculados".

A Constituição do Uruguai, assim como a da Argentina, é bastante sucinta a respeito dos marcos regulatórios educacionais. Babinski (2010) salienta que, ao longo do texto constitucional do país, o tema da educação é abordado em apenas sete artigos, não dispõe de um capítulo específico e estão salpicados ao longo do corpo da Carta Magna. Assim sendo, cabe à legislação infraconstitucional tratar do tema com maior amplitude, bem como definir princípios e diretrizes para a organização da educação nacional.

A Lei Geral da Educação Uruguaia $n^{\circ}$. 18.437/2008 define, no artigo $n^{\circ}$. 20, que o Sistema Nacional de Educação consiste em um conjunto de propostas educacionais integradas e articuladas para todas as pessoas ao longo da vida. $\mathrm{O}$ artigo $\mathrm{n}^{\circ} .21$ trata da organização da educação formal do país, que é estruturada por níveis e modalidades (Educação rural; Educação de jovens e adultos; Educação de pessoas com deficiência e Educação a distância) que compõem as diferentes fases do processo educativo, garantindo a sua unidade e a continuidade. Os níveis são: educação inicial, educação primária, educação média básica, educação média superior, educação terciária e pós-graduação, conforme artigo nº 22 (SOUZA, 2017).

A estruturação do ensino uruguaio no que refere à educação básica corresponde: educação infantil voltada para crianças de três, quatro e cinco anos; educação primária, contempla crianças de seis a 11 anos; educação média básica que abarcará o ciclo de ensino pós-primário imediato para crianças de 12 a 14 anos; e a etapa subsequente compreende a educação média superior, que contemplará adolescente de 15 a 17 anos. Essa etapa oferecerá três categorias de ensino: educação geral, que permitirá a continuidade no ensino superior (escolas gerais elevadas); tecnologia, que irá manter o ensino superior e emprego (escolas secundárias e tecnológicas); e formação técnica e profissional, que será voltada, principalmente, para a colocação no mercado de trabalho (URUGUAI, 2009).

No Uruguai, o Sistema Nacional de Educação é centralizado em consonância com a estrutura político-administrativa da condição de ser um Estado Unitário. Sobre os órgãos do Sistema do país, a Lei Geral da Educação Uruguaia n ${ }^{\circ}$. 18.437/2008 define, em seu artigo nº. 43, que a Comissão Nacional de Educação tem a natureza de deliberação sobre as políticas educacionais e terá caráter de assessoramento e de consulta para promover as articulações das políticas educativas com outras políticas públicas; integrar comissões de assessoramento e de coordenação de temas vinculados à referida lei e outras normas da matéria educativa, e propiciar conferências, congressos e fóruns sobre tema relacionados à área (SOUZA, 2017). 
A referida Comissão dispõe de autonomia para definir suas próprias regras de funcionamento e o Ministério da Educação e Cultura garantirá apoio administrativo, organizacional, técnico e orçamento exigidos pela Comissão para cumprir as suas tarefas, conforme previsão legal do artigo n ${ }^{\circ} .42$ da Lei Geral da Educação do país (URUGUAI, 2009).

Assim como o Paraguai, o Uruguai apresenta uma configuração de Sistema Nacional de Educação convergente com seus governos centralizados. Contudo, diferente do outro país mercosulino, a organização da educação uruguaia é determinada pelas avaliações e decisões da Comissão Nacional de Educação, órgão deliberativo sobre as políticas públicas educativas e que consta, em sua composição, com representantes dos diversos segmentos da educação pública, privada e da sociedade civil (BABINSKI, 2010).

Cury (2008) destaca que a maioria dos países centralizados efetivou a operacionalização dos seus respectivos sistemas nacionais de educação, como é o caso do Uruguai, no qual compete ao poder central a direção das políticas educacionais de modo que estejam sintonizadas para a garantia de uma coesão nacional, um padrão comum, uma perspectiva de ação educacional voltada para a efetivação do direito à educação a todos, indistintamente.

Por outro lado, ao fazer essa ponderação, o autor não está afirmando que os regimes federativos carecem de condições político-administrativas que permitam a consolidação de um Sistema Nacional de Educação, mas sim detectando a complexa engenharia institucional, jurídica e financeira para tal efetivação, sobretudo em países com dimensão continental, como o Brasil, por exemplo, no qual há a histórica dificuldade de articulação e cooperação dos diferentes polos de poder entre União, Estados e municípios ou, em outros termos, a relação centralização e descentralização (CURY, 2008).

A constituição venezuelana trata sobre a organização da educação do país de forma sucinta. No seu artigo $\mathrm{n}^{\circ}$. 103, destaca que o Estado criará e financiará instituições e serviços para assegurar o acesso e a permanência no sistema educativo do país. Quanto à distribuição de competências entre os três entes federados do país, que são denominadas de Poder Público Nacional, Poder Público Estadual e Poder Público Municipal, o artigo nº 156 define que é uma das responsabilidades do Poder Publico Nacional as políticas e os serviços nacionais de educação e saúde (VENEZUELA, 1999).

É importante registrar que, conforme a Constituição do país, Estados e Municípios são entidades autônomas e iguais, dispõem de plena personalidade jurídica e são obrigadas a manter a independência, soberania e integridade nacional para cumprir e fazer cumprir a Carta Magna e as leis da República. Quanto aos Estados, não há especificação, no texto constitucional, de suas 
atribuições referentes à educação. No tocante aos municípios, são responsáveis pela educação pré-escolar, como é salientado no artigo $\mathrm{n}^{\circ} .178$.

A delimitação de responsabilidades asseguradas na Carta Magna venezuelana não corresponde, necessariamente, a uma organização político-administrativa descentralizada, pois, segundo Araújo (2010), o país apresenta uma lógica de organização pautada pelo federalismo centralizado, em que as unidades subnacionais são agentes administrativos do governo central. Lizbona (2013) também ressalta essa condição de centralização do poder em um país de regime federado, que não está materializada apenas em nível jurídico, mas também no âmbito fiscal e econômico.

Como se explicó, tanto a nivel político-institucional como a nivel fiscaleconómico, es posible reconocer una tensión entre la federación y los estados, favoreciendo la verticalización del poder en manos del Ejecutivo. [...] En suma, la trayectoria del federalismo venezolano correspondió a la centralización. y la fuerte acumulación del poder presidencial de Hugo Chávez no fueron ventajosos para un federalismo descentralizado y sí para la centralización del poder nacional. (LIZBONA, 2013, p. 130)

A Lei orgânica da Educação da Venezuela dedica um capítulo para tratar da organização do sistema educacional. $\mathrm{O}$ artigo $\mathrm{n}^{\circ} .24$ traz a definição sobre o sistema do país. Trata-se de um conjunto orgânico e estruturado que é composto por subsistemas, níveis e modalidades conforme os estágios de desenvolvimento humano e se pauta nos princípios da unidade, responsabilidade, interdependência e flexibilidade. O sistema é integrado por políticas, escolas, serviços e comunidades que visam garantir o processo de ensino e da formação permanente da pessoa, independentemente da idade, com relação as suas capacidades, diversidade étnica linguística e cultural, considerando, nesse processo, as necessidades, particularidades e potencialidades locais, regionais e nacional.

O sistema venezuelano está organizado em um subsistema de educação básica, em um subsistema de educação universitária e pelas modalidades educacionais que compreendem: Educação especial, Educação de jovens e adultos, Educação em fronteiras, Educação rural, Educação para as artes, Educação militar, Educação intercultural, Educação intercultural bilíngue (VENEZUELA, 2009).

O subsistema de educação básica contempla os níveis compostos pela educação inicial, o ensino primário e secundário. O nível de formação inicial compreende as etapas de educação materna e pré-escola destinadas a crianças com idade entre zero e seis anos. O nível de educação primária é constituído de seis anos e conduz à obtenção do certificado de educação primária. $\mathrm{O}$ nível médio de educação inclui duas opções: o ensino secundário geral, correspondente aos 
últimos cinco anos (do primeiro ao quinto ano), e o ensino técnico, com duração de seis anos (do primeiro ao sexto ano). Ambas as opções levam à obtenção do título correspondente (VENEZUELA, 2009).

De acordo com Souza (2017), no que concerne à educação escolar básica, com a aprovação da Lei Orgânica de Educação em 2009, ela passa a dispor de um aparato legal do Estado Venezuelano que tem gestado e implantado políticas públicas a partir da concepção de um sistema educativo pautado na justiça social. Nessa vertente, trata-se de um instrumento normativo que constitui um marco jurídico de proteção ao direito à educação no país.

Quanto aos níveis de ensino, podemos perceber que os países membros do Mercosul organizam a educação básica a partir de três módulos/etapas/unidades: o primeiro voltado para a educação inicial ou educação infantil, o segundo compreende a educação primária ou ensino fundamental e o terceiro corresponde à educação média. Como podemos visualizar no Quadro 1, apenas o Uruguai destoa dessa divisão, na medida em que assegura duas etapas do ensino médio.

Quadro 1 - Organização da educação básica nos países do Mercosul

\begin{tabular}{ll}
\hline Países & Estrutura da educação básica \\
Argentina & Educação Inicial \\
& Educação Primária \\
Brasil & Educação Secundária \\
& Educação Infantil \\
& Ensino Fundamental \\
Paraguai & Ensino Médio \\
& Educação Inicial \\
& Educação Escolar Básica \\
Uruguai & Educação Média \\
& Educação Inicial \\
& Educação Primária \\
& Educação Média Básica \\
Venezuela & Educação Média Superior \\
& Educação Inicial \\
& Educação Primária \\
& Educação Média \\
\hline
\end{tabular}

Fonte: Elaboração própria com base em Argentina (2006), Brasil (1996), Paraguai (1998), Uruguai (2009) e Venezuela (2009). 


\section{Considerações finais}

Foi possível abstrair das análises normativas que o Brasil dispõe de um arcabouço constitucional mais amplo sobre a organização educacional. Argentina, Paraguai, Uruguai e Venezuela demandam da legislação infraconstitucional para regulamentar a estruturação da educação. Porém, mesmo com a proteção jurídica mais sólida decorrente do texto da Carta Magna, o Brasil carece de um marco legal que normatize seu Sistema Nacional de Educação, diferentemente dos demais países do Mercosul, que instituíram essa estruturação em suas respectivas legislações educacionais.

Embora o Brasil não disponha da normatização de um Sistema Nacional de Educação, a distribuição de competências entre os governos subnacionais configura no seu marco legal, assim como na Argentina. A Carta Magna Brasileira versa sobre a estrutura da sua organização educacional, expondo acentuada descentralização administrativa, reforçada pelo federalismo, visando à autonomia dos entes federados. A Argentina delineia o desenho institucional do seu sistema educacional de forma articulada e unificada, mas é preciso registrar que, mesmo após as legislações atuais que garantem maior descentralização dos serviços públicos, o governo central do país ainda concentra as competências atinentes à gestão, regulamentação e financiamento educacional (BABINSKI, 2010).

Ainda que a Venezuela também tenha sua organização político-administrativa pautada pelo federalismo, denota-se, em suas legislações, acentuada centralização das atribuições inerentes à prestação de serviços públicos, dentre eles, a educação. Já Paraguai e Uruguai, embora demonstrem nos seus respectivos marcos legais previsões de descentralização das políticas públicas, apresentam um arranjo institucional educacional que é focado na atuação do governo central. Esse quadro se deve muito em função da condição de ambos serem Estados unitários.

Todos os países também preveem o oferecimento de modalidades diferentes de ensino voltadas para as necessidades específicas de determinados segmentos populacionais, objetivando consagrar a igualdade no direito à educação, atendendo, dessa forma, às particularidades de indivíduos ou grupos de caráter permanente ou temporal. Essas modalidades são oferecidas dentro dos níveis e/ou etapas de ensino mencionadas, devendo cumprir os requisitos previstos nas legislações específicas dos países para cada uma delas. Notamos que Paraguai, Venezuela e Argentina dispõem de um número mais amplo de modalidades, enquanto Brasil e Uruguai oferecem menos. $\mathrm{O}$ aspecto quantitativo, nesse caso, representa as particularidades e exigências inerentes às demandas educacionais de cada país. 
Constituir uma organização do sistema de ensino significa, prioritariamente, assumir um compromisso com as demandas sociais pela garantia do direito à educação. Assim, as organizações de ensino dos países membros do Mercosul, mesmo com lacunas normativas e diferenças, dispõem de aparatos legais que normatizam uma estruturação educacional, o que representa a sistematização de políticas públicas educacionais e um compromisso jurídico com a proteção do direito educacional.

Se considerarmos o contexto histórico dos países membros do Mercosul, é inegável o avanço normativo na definição e sistematização da organização dos sistemas de ensino como um dos instrumentos de garantia do direito à educação. Por outro lado, há uma distância entre o marco legal e a sua efetividade em termos de garantia de acesso, permanência e qualidade de ensino. A educação precisa ser compreendida e assumida enquanto um direito, mas o arcabouço jurídico, sozinho, não garante seu cumprimento apenas por existir. É preciso, pois, garantir as condições concretas para sua implementação.

\section{REFERÊNCIAS}

ARAÚJO, G. C. Constituição, federação e propostas para o novo Plano Nacional de Educação: análise das propostas de organização nacional da educação brasileira a partir do regime de colaboração. Educação e Sociedade, Campinas, v. 31, n. 112, p. 749-768, 2010.

ARGENTINA. Constitución Nacional da Argentina. Senado de La Nación Argentina: Buenos Aires. 1994.

ARGENTINA. Ley no. 26.206 del 14 diciembre 2006. Ley de Educacion Nacional. Senado de La Nación Argentina: Buenos Aires. 2006.

BARRETO, A. A. B. Eleições municipais comparadas: a escolha do chefe do executivo no Brasil e no Uruguai e o impacto sobre os sistemas partidários locais (2000 - 2005). Revista Brasileira de Ciência Política, Brasília, n. 7, p. 285-318, 2012.

BRASIL. Constituição da República Federativa do Brasil de 1988. Constituição da República Federativa do Brasil. Brasília: Senado, 1988.

BRASIL. Lei no 9.394 de 20 de dezembro 1996. Estabelece as diretrizes e bases da educação nacional. Diário Oficial da República Federativa do Brasil, Brasília: 1996.

BRASIL. Lei no 13.005 de 25 de junho de 2014. Aprova o Plano Nacional de Educação PNE e dá outras providências. Diário Oficial da República Federativa do Brasil, Brasília: 2014.

CRUZ, R. E. Federalismo e educação: um pacto a se rever. Retratos da Escola, Brasília, v. 6, n. 10, p. 65-78, 2012. 
CURY, C. R. J. A educação básica como direito. Cadernos de pesquisa, São Paulo, v. 38, n. 134, p. 292-303, 2008.

DOURADO, L. F. Sistema nacional de educação, federalismo e os obstáculos ao direito à educação básica. Educação e Sociedade, Campinas, v. 34, n. 124, p. 761-785, 2013.

LIZBONA, C. A. La paradoja de la estabilidad política en Venezuela: un federalismo centralizado. Revista Provincia, Caracas, n. 29, p. 111-134, 2013.

MOLINIER, L. El Sistema educativo obligatorio y gratuito em paraguay: fundamentos para sua universalización y calificación. In: ORTIZ, L. (Org.). La educación en su entorno: Sistema educativo y políticas públicas en Paraguay. Assuncion: CADEP, p. 15-56, 2014.

OLIVEIRA, J. F.; MORAES, K. N.; DOURADO, L. F. O financiamento da educação básica: limites e possibilidades. MEC: Escola de Gestores, 2009.

PARAGUAI. Constitución de la República de Paraguay. Assunción. 1992.

PARAGUAI. Ley nº 1.264 del 26 mayo 1998. Ley General de Educación. Assunción, 1998.

SAVIANI, D. Sistema Nacional de Educação articulado ao Plano Nacional de Educação.

Revista Brasileira de Educação, Rio de Janeiro, v. 15, n. 44, p. 380-393, 2010.

SOUZA, K. R. Direito à educação nos países membros do Mercosul: um estudo comparado. 2017. 346f. Tese (Doutorado em Educação Escolar) - Universidade Estadual Paulista, Araraquara-SP, 2017.

TROJAN, R. M. Estudo comparado sobre políticas educacionais na América Latina e a influência dos organismos multilaterais. Revista Brasileira de Política e Administração da Educação, Brasília, v. 26, n. 1, p. 55-74, jan./abr. 2010.

URUGUAI. Constituicion de La Republica com las modificaciones plebiscitadas el 26 de noviembro de 1989, el 26 de noviembro de 1994 y el 8 de diciembro de 1996. Montividéu. 1967.

URUGUAI. Ley no $\mathbf{1 8 . 4 3 7}$ del 16 enero 2009. Ley Genera de Educación. Montividéu: 2009.

VENEZUELA. Constitución de la República Bolivariana de Venezuela. Caracas: 1999.

VENEZUELA. Ley nº $\mathbf{0 . 9 2 9}$ del 15 de agosto de 2009. Ley Orgánica de Educación. Caracas: 2009. 


\section{Como referenciar este artigo}

SOUZA, K. R.; KERBAUY, M. T. M. A organização dos sistemas de ensino nos países do Mercosul. Revista Ibero-Americana de Estudos em Educação, Araraquara, v. 14, n. esp. 3, p. 1670-1687, out., 2019. E-ISSN: 1982-5587. DOI: 10.21723/riaee.v14iesp.3.12752

Submetido em: 25/03/2019

Revisões requeridas: 26/04/2019

Aceito em: 30/06/2019

Publicado em: 30/08/2019 